\title{
ANALISIS PENERAPAN SISTEM APLIKASI REDMINE PADA GRUP PRDC PT. ANABATIC DIGITAL RAYA DENGAN MENGGUNAKAN PENDEKATAN MODEL UTAUT (UNIFIED THEORY OF ACCEPTANCE AND USE OF TECHNOLOGY)
}

\author{
Yohanes Kevin Natanael ${ }^{1}$, Augie David Manuputty ${ }^{2}$ \\ ${ }^{1,2}$ Fakultas Teknologi Informasi Universitas Kristen Satya Wacana Salatiga
}

Article Info:

Dikirim: 26 Maret 2019

Direvisi: 08 Mei 2019

Diterima: 08 Mei 2019

Tersedia Online: 29 Juni 2019

Penulis Korespondensi:

Yohanes Kevin Natanael

Fakultas Teknologi Informasi

Universitas Kristen Satya Wacana,

Salatiga, Indonesia

Email: ykevinnatanael@gmail.com

\begin{abstract}
Abstrak: Tujuan dilakukannya penelitian ini adalah untuk menguji faktor-faktor yang mempengaruhi minat dari penggunaan sistem aplikasi Redmine, pada karyawan grup PRDC (Product Research and Development Center) PT. Anabatic Digital Raya, Tangerang. Dengan menggunakan pendekatan model UTAUT (Unified Theory of Acceptance and Use of Technology), Data yang didapatkan menggunakan metode kuantitatif dengan cara melakukan penyebaran kuisioner langsung terhadap karyawan yang menggunakan sistem aplikasi Redmine. Data dianalisis dengan menggunakan aplikasi SmartPLS. Dan hasil penelitian ini menunjukan bahwa Social Influence berpengaruh positif terhadap Behavior Intention pada penggunaan sistem aplikasi Redmine.
\end{abstract}

Kata kunci: teknologi informasi; UTAUT; redmine.

\begin{abstract}
The purpose of this study is to examine the factors that influence interest of using Redmine System, to employees of group PRDC (Product Research and Development Center) PT. Anabatic Digital Raya, Tangerang. Using the UTAUT (Unified Theory of Acceptance and Use of Technology) approaching model, the data obtained using quantitative method by distributing questionnaries directly to employees that using Redmine. And the data were analyzed using SmartPLS, and the result is Social Influence has a positive effect on Behavior Intention on the use of the Redmine application system.
\end{abstract}

Keywords: information technology; UTAUT; redmine. 


\section{PENDAHULUAN}

Teknologi Informasi (TI) melalui penerapannya saat ini, sudah berkembang begitu pesat dan menjadi suatu aspek yang keberadaannya tidak akan bisa lepas dari aktivitas manusia. Sistem informasi yang memudahkan pengguna akan menimbulkan perasaan pada diri seseorang, bahwa sistem yang digunakannya berguna dan menimbulkan rasa yang nyaman ketika bekerja menggunakan sistem tersebut [1]. Akan tetapi dalam penerapan dari teknologi informasi yang digunakan bisa terjadi kegagalan yang disebabkan dari beberapa faktor baik itu internal maupun eksternal [2], dan tiap keberhasilan dari sistem yang diterapkan bergantung pada pengguna dari teknologi informasi yang digunakan [3], untuk mengetahui tingkat keberhasilan dari penerapan sistem yang telah diterapkan, teknologi yang sudah diterapkan dapat diukur guna mengetahui pengguna dapat menerima dan memahami penggunaan teknologi [4].

Unified Theory of Acceptance and Use of Technology (UTAUT) merupakan salah satu metode pendekatan model penerimaan teknologi dan dapat menjelaskan perilaku dari pengguna yang diusulkan oleh Viswanath Venkatesh, dkk pada tahun 2003 [5]. Dimana pendekatan model yang digunakan menggabungkan 8 model sekaligus yaitu: Technology Acceptance Model (TAM), The Innovation Diffusion Theory (IDT), The Theory of Reasoned Acceptance (TRA), The Theory of Planned Behavior (TPB), The Motivational Model (MM), A Model of Combining TAM and TPB (C - TAM - TPB), The Model of PC Utilization (MPCU), dan The Social Cognitive Theory (SCT) [5]. Setelah kedelapan model tersebut di evaluasi maka ditemukannya tujuh konstruk yang memiliki pengaruh signifikan terhadap Behavior Intention dan Use Behavior dalam satu maupun lebih dari masing - masing modelnya tersebut. Konstruk yang dihasilkan berupa Performance Expentancy, Effort Expentancy, Social Influence, Facilitating Conditions, Attitude Towards using Technology, dan Self-Efficiancy. Kemudian dengan pengujian yang lebih lanjut, ditemukanlah empat konstruk utama yang berperan penting kepada Behavior Intention dan Use Behavior, yaitu Performance Expentancy, Effort Expentancy, Social Influence dan Facilitating Condition. Selain variabel tersebut terdapat 4 moderator yang memoderasi konstruk utama tersebut seperti jenis kelamin (Gender), umur (Age), pengalaman (Experience), dan kesukarelaan pengguna (Voluntariness of Use) [4].

Sistem aplikasi Redmine merupakan salah satu sistem open source gratis berbasis web untuk manajemen proyek, dibuat dengan menggunakan framework Ruby on Rails. Dengan aplikasi ini pengguna dapat mengelola berbagai proyek dan sub proyek yang akan di laksanakan, sistem aplikasi redmine dapat dikonfigurasikan sesuai dengan kebutuha. PT Anabatic Digital Raya terkhususnya grup PRDC (Product Research and Development Center) menggunakan sistem aplikasi Redmine dikarenakan sebelum menggunakan sistem aplikasi tersebut banyak data - data dokumen proyek yang tidak lengkap, serta keperluan yang membutuhkan persetujuan masih tradisional sehingga birokrasi menjadi lamban dikarenakan harus menunggu. Dengan adanya Redmine pada grup PRDC diharapkan mampu untuk mengurangi permasalahan yang terjadi sebelumnya. Untuk mengetahui sejauh mana pengaruh manfaat dan evaluasi yang didapatkan dari sistem aplikasi Redmine yang diimplementasikan pada PT. Anabatic Digital Raya terkhususnya pada grup PRDC digunakannya pendekatan UTAUT (Unified Theory of Acceptance and Use of Technology), dimana model UTAUT terdapat 4 konstruk variabel utama yaitu Performance Expectacy, Effort Expectacy, Social Influence, dan Facilitating Condition dengan 2 moderasi yang digunakan yaitu Age dan Experience [6].

Metode UTAUT seperti yag ditunjukkan pada gambar 1 merupakan salah satu metode yang diperkenalkan oleh Viswanath Venkatesh, dkk pada tahun 2003. Model UTAUT digunakan untuk mengetahui sejauh mana penerimaan teknologi yang telah digunakan dengan menggambungkan elemen - elemen pada 8 model penerimaan teknologi terkemuka yang pernah ada yaitu Theory of Reasoned Action (TRA), Technology Acceptance Model (TAM), Motivation Model (MM), Theory of Planned Behavior (TPB), Combined TAM \& TPB, Model of PC Utilization (MPTU), Innovation Diffusion Theory (IDT), dan Social Cognitive Theory (SCT) untuk mengetahui penerimaan teknologi terkini [5].

\subsection{UTAUT (Unified Theory of Acceptance and Use of Technolgy )}

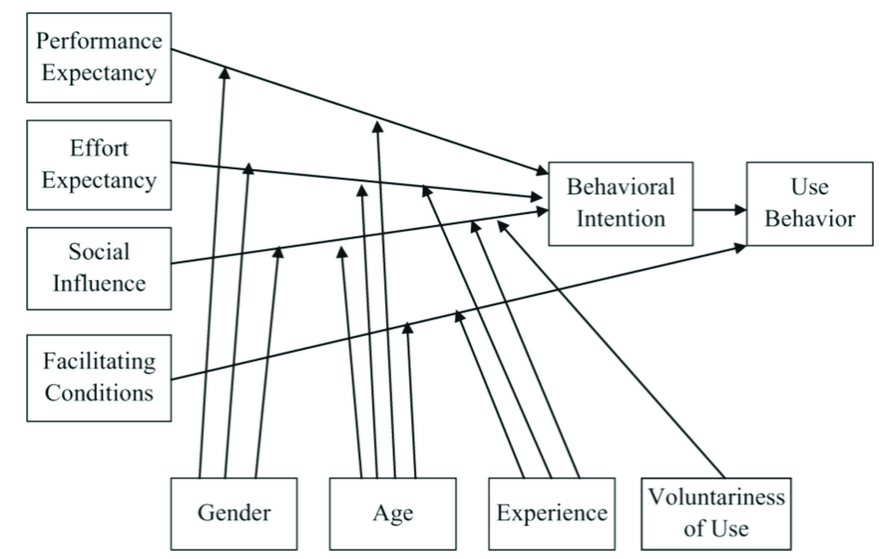

Gambar 1. Model UTAUT [5] 
1) Performance Expectancy

Performance Expectancy merupakan variabel mengenai tingkat kepercayaan pengguna guna menunjukan sejauh mana sistem yang digunakan oleh pengguna dapat membantu dan meningkatkan kinerjanya. Terdapat lima buah konstruksi yang berhubungan dengan Performance Expectancy yaitu percieved usefulness (TAM/TAM2 dan C-TAM-TPB), extrinsic motivation (MM), job-Fit (MPCU), relative Advantage (IDT) dan outcome expectations (SCT) [5].

2) Effort Expectancy

Effort Expectacy adalah variabel yang digunakan sebagai alat ukur tingkat kemudahan dalam penggunaan sistem. Sistem yang digunakan oleh pengguna diharapkan dapat memudahkan dan meningkatkan dari sisi kinerja, dengan kemudahan yang didapatkan dapat meningkatkan keinginan pengguna untuk menggunakan sistem. Terdapat tiga buah konstruksi dari model yang berbeda dari Effort Expectancy yaitu Percieved Ease to Use (TAM/TAM2), Complexity (MPCU) dan Ease of Use (IDT) [5].

3) Social Influences

Social Influences digunakan untuk mengukur pengaruh sosial terhadap suatu individu agar dapat merasa penting dan percaya bahwa ia harus menggunakan sistem yang baru. Mandat penggunaan juga mempengaruhi penggunaan sistem, kepatuhan yang bersifat wajib memberikan suatu efek langsung pada niat user untuk dapat memberikan niat langsung bagi para pengguna untuk menggunakan suatu aplikasi. Terdapat 3 buah konstruksi dari model yang berbeda terhadap Social Influence yaitu Subjective Norm (TRA, TAM2, TPB/DTPB dan C-TAM-TPB), Social Factor (MPCU) dan Image (IDT) [5].

4) Facilitating Conditions

Facilitating Condition adalah suatu variabel yang dapat digunakan untuk mengukur sejauh mana suatu individu dapat mempercayai bahwa suatu infrastruktur dari suatu organisasi baik teknis maupun organisasional dapat didukung dengan penggunaan dari sebuah sistem. Terdapat 3 buah konstruksi dari model yang berbeda terhadap Facilitating Conditions yaitu Perceived Behavioral Control (TPB/ DTPB, CTAM-TPB), Facilitating Conditions dan Compability (IDT) [5].

5) Behavioral Intention

Behavioral Intention digunakan untuk menunjukan suatu perilaku dari niat (rencana yang digunakan untuk menggunakan suatu sistem) yang berdasarkan penggunaan sistem mengenai keuntungan yang didapatkan. Ketika seorang pengguna mengetahui bahwa dengan menggunakan sistem dapat memudahkan suatu proses pekerjaan menjadi mudah maka dapat lebih mudahlah niat untuk menggunakan sistem tersebut [5].

6) Use Behavior

Use Behavior digunakan untuk menunjukan perilaku dari suatu individu atau pengguna untuk mengetahui seberapa sering digunakan oleh pengguna tersebut. Dengan semakin banyak informasi mengenai pengguna yang percaya bahwa sistem yang digunakan dapat memberikan manfaat yang dapat meningkatkan kinerja serta mempermudah dalam pengguna menyelesaikan tugas dan tanggung jawabnya maka frekuensi dari penggunaan sistem akan semakin meningkat serta dengan kepercayaan dari fasilitas sistem yang ada akan meningkatkan pemakaian dari sistem itu sendiri [5].

7) 4 Moderator

Disisi lain dari konstruk - konstruk yang mendukung dari metode UTAUT pada penelitian ini terdapat 4 moderator yang berpengaruh pada konstruk - konstruk tersebut yaitu Gender (Jenis Kelamin), Age (Umur), Experience (Pengalaman) dan Voluntariness of Use (Kesukarelaan pengguna) [5].

\subsection{Structural Equation Model (SEM) \& SmartPLS}

Structural Equation Modeling (SEM) merupakan salah satu alat atau teknik statistik yang digunakan oleh peneliti guna menganalisa data yang bersifat kuantitatif, teknik SEM sendiri memiliki kemampuan yang mampu untuk menganalisa persamaan regresi berganda maupun analisa jalur. Teknik SEM menghubungkan hubungan rumit antara satu atau beberapa variabel dengan satu atau beberapa variabel dimana masing - masing variabel telah dikonstruksikan oleh beberapa indikator. Pendekatan yang dilakukan dengan teknik ini dengan mengintegerasikan dua analisa yang telah dilakukan yaitu analisis faktor dan analisis jalur (Path Analysis), dan dengan SmartPLS yang merupakan salah satu aplikasi statistik yang dapat digunakan, dengan menggunakan teknik SEM pada metode statistik dapat disajikannya data - data guna mencapai tujuan dari penelitian yang dilakukan serta dapat menjawab permasalahan dari penelitian.

\section{METODOLOGI PENELITIAN}

Dalam penelitian ini digunakannya metode penelitian menggunakan pendekatan kuantitatif, penelitian kuantitatif bertujuan untuk menjelaskan hubungan, perbedaan antara satu variabel dengan variabel yang lainnya [7], pada data yang telah dikumpulkan akan digunakan untuk menganalisis pengaruh dari variabel independen terhadap variabel dependen. Data yang diambil merupakan data primer yang diambil langsung terhadap objek penelitian, yaitu dengan memberikan kuisioner kepada karyawan grup PRDC PT. Anabatic Digital Raya dengan tujuan untuk menguji hipotesis yang telah ditetapkan. 


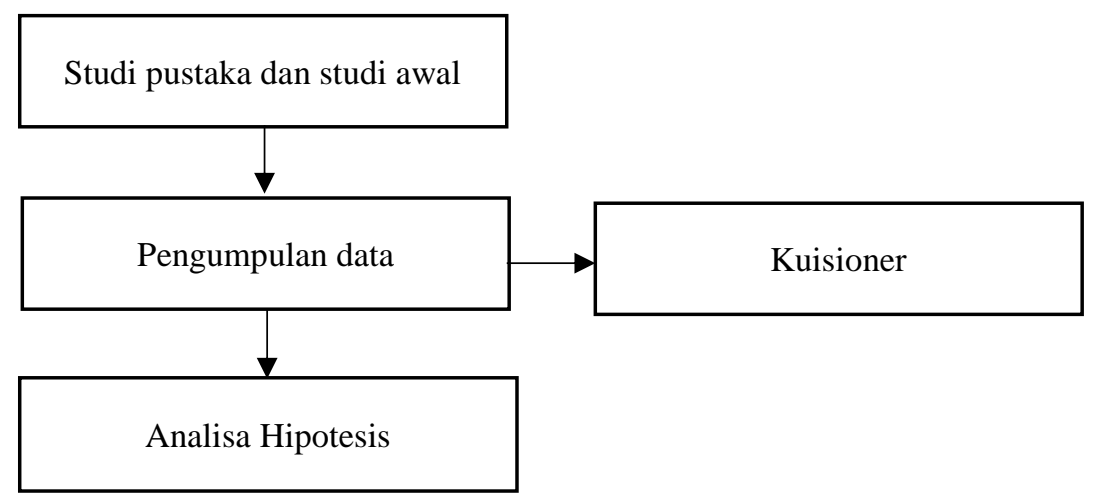

Gambar 2. Tahapan Penelitian

\subsection{Studi Pustaka dan Studi Awal}

Tahap pertama yang dilakukan yaitu studi pustaka dan studi awal, dimana peneliti mencari dan mengupulkan informasi yang berkaitan dengan penelitian yang dilakukan. Kemudian model penelitian yakni UTAUT lalu melakukan studi awal terhadap lokasi studi kasus dan mencari informasi mengenai sistem aplikasi Redmine pada karyawan PT. Anabatic Digiral Raya.

\subsection{Pengumpulan Data}

Tahap kedua yang dilakukan adalah peneliti melakukan pengumpulan data dengan cara melakukan penyebaran kuisioner terhadap responden terkait, yakni responden (karyawan) pada grup PRDC yakni sejumlah kurang lebih 74 orang yang terdiri dari 9 divisi yang berbeda. Ketika data yang sudah didapatkan oleh peneliti sudah cukup maka dilakukannya.

\subsection{Analisa Hipotesis}

Tahap ketiga yaitu menganalisis hipotesis dengan data yang didapatkan dari hasil kuisioner yang telah diisi oleh responden terkait. Analisis hasil kuisioner tersebut dilakukan dengan teknik SEM (Structural Equation Model) dan diproses dengan aplikasi SmartPLS. Kemudian dengan bantuan aplikasi SmartPLS peneliti mampu mengetahui sejauh mana efektif dari penggunaan sistem aplikasi Redmine di kalangan grup PRDC PT. Anabatic Digital Raya.

\section{HASIL DAN PEMBAHASAN}

Data yang telah didapatkan memberikan informasi secara singkat terkait dengan responden yang dijadikan sebagai objek dari penelitian ini, data yang dikumpulkan oleh peneliti dikirimkan langsung kepada karyawan grup PRDC PT. Anabatic Digital Raya. Kuisioner yang disebarkan oleh peneliti sebanyak 74 orang dan kuisioner yang mendapatkan tanggapan hanya sebanyak 65 orang.

Berdasarkan 65 orang responden yang ikut berpatisipasi mayoritas berusia $21-30$ Tahun dengan persentase sebesar $81,5 \%$, usia $<20$ Tahun dan $31-40$ Tahun memiliki persenan masing - masing sebesar 4,6\% dan > 41 Tahun sebesar 9,2\%, kemudian diketahui mayoritas responden berjenis kelamin laki - laki sebesar 53,8\% sedangkan perempuan hanya $46,2 \%$. Selanjutnya diketahui pendidikan yang telah dilalui oleh responden mayoritas S1 sebesar 75,4\%, SMU/SMK sebesar 15,4\%, serta S2 dan D2/D3 memiliki persenan masing - masing sebesar $4.6 \%$, selanjutnya pengalaman bekerja dari responden mayoritas $>3$ Tahun dengan persentase $41,5 \%,<1$ Tahun sebesar $32,3 \%$ dan $1-3$ Tahun sebesar $26,2 \%$. 


\subsection{Hipotesis}

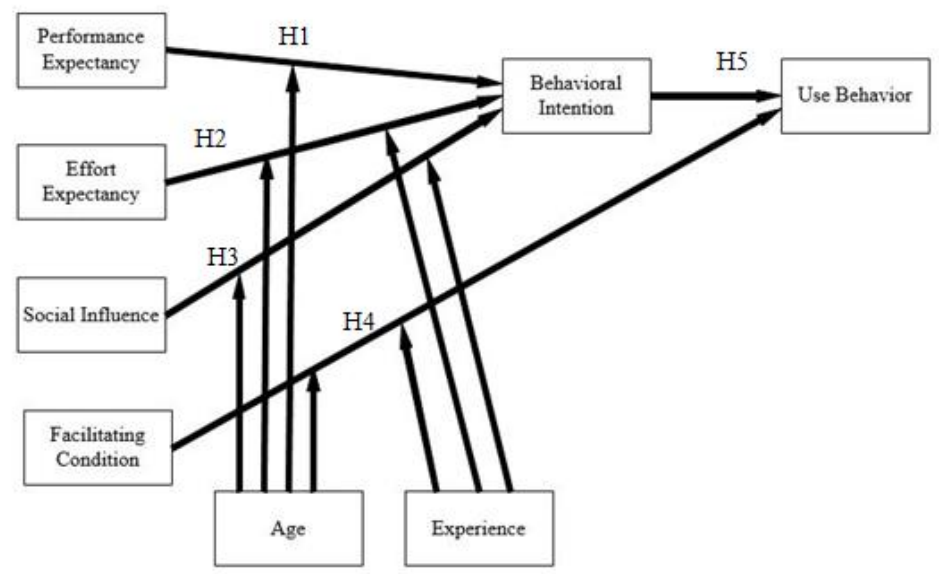

Gambar 3. Alur Hipotesis

Adapun hipotesis yang dibuat berdasarkan dimensi dan variabel UTAUT sebagai berikut ini:

(PE) Performance Expentancy, (EE) Effort Expentancy, (SI) Social Influence, (FC) Facilitating Condition. Dan Variabel Control berupa (AGE) age, (EX) Experience, Behavior Intention (BI) dan Use Behavior (UB). Dari variabel - variabel tersebut akan di formulasikan dengan suatu rancangan hipotesis sebagai berikut:

a) H1 (PE) Performance Expentancy memiliki pengaruh terhadap Behavior Intention (BI) untuk menggunakan sistem Redmine pada grup PRDC dengan variabel control (AGE) Age.

b) H2 (EE) Effort Expentancy memiliki pengaruh terhadap Behavior Intention (BI) untuk menggunakan sistem Redmine pada grup PRDC dengan variabel (AGE) Age dan (EX) Experience.

c) H3 (SI) Social Influence memiliki pengaruh terhadap Behavior Intention (BI) untuk menggunakan sistem Redmine pada grup PRDC dengan variabel (AGE) Age dan (EX) Experience.

d) $\mathrm{H} 4$ (FC) Facilitating Condition memiliki pengaruh terhadap Use Behavior (UB) untuk menggunakan sistem Redmine pada grup PRDC dengan variabel (AGE) Age dan (EX) Experience.

e) H5 (BI) Behavioral Intention memiliki pengaruh terhadap Use Behavior (UB) sistem Redmine pada grup PRDC.

Untuk konstruk pendukung sebagai moderasi seperti Gender telah diselidiki bahwa tidak memiliki pengaruh yang signifikan terhadap penggunaan sistem aplikasi Redmine, dalam pemanfaatannya grup PRDC menggunakan sistem Redmine tersebut tidak terkait mengenai perbedaan Gender. Moderator Voluntariness of Use tidak digunakan juga dikarenakan sebagian besar pengguna dapat untuk menggunakan sistem aplikasi tersebut sehingga tidak ada perbedaan konstruk kesukarelaan.

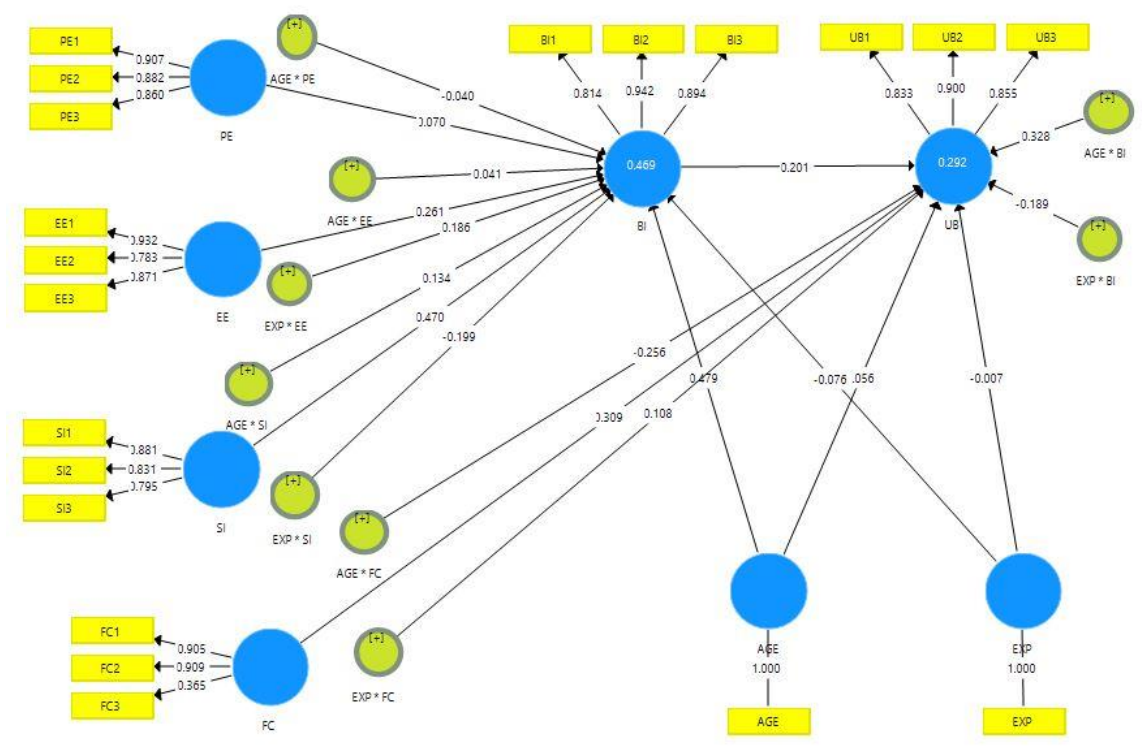

Gambar 4. Model Perhitungan UTAUT

Pada gambar 4 model perhitungan UTAUT menjelaskan mengenai pola hubungan antara variabel terhadap indicator yang digunakan. Setelah memasukan nilai yang didapatkan dari hasil responden tersebut dan mengikuti 
model dari UTAUT, ketika telah dilakukannya perhitungan melalui aplikasi SmartPLS, akan didapatkan hasil sebagai mana tertera pada diagram model perhitungan UTAUT 3.1.

\subsection{Uji Validitas dan Reabilitas}

Dengan menggunakan software SmartPLS dapat mengkaji variabel - variabel yang digunakan valid tidaknya suatu variabel. Dari hasil report SmartPLS, apabila suatu nilai dari korelasi $>0.7$ maka variabel dari pertanyaan dapat dinyatakan lulus uji validitas dan sebaliknya apabila nilai korelasinya $<0.7$, maka variabel dari pertanyaan tersebut dinyatakan tidak valid. Berikut hasil dari tabel uji validitas dari tiap variabel - variabel pertanyaan yang digunakan:

Tabel 1. Uji validity variabel pernyataan

\begin{tabular}{|c|c|c|}
\hline $\mathrm{NO}$ & VARIABEL & HASIL \\
\hline 1 & PE1 & 0.907 \\
\hline 2 & PE2 & 0.882 \\
\hline 3 & PE3 & 0.860 \\
\hline 4 & EE1 & 0.932 \\
\hline 5 & EE2 & 0.783 \\
\hline 6 & EE3 & 0.871 \\
\hline 7 & SI1 & 0.881 \\
\hline 8 & SI2 & 0.831 \\
\hline 9 & SI3 & 0.795 \\
\hline 10 & $\mathrm{FC} 1$ & 0.905 \\
\hline 11 & $\mathrm{FC} 2$ & 0.909 \\
\hline 12 & FC3 & 0.865 \\
\hline 13 & UB1 & 0.814 \\
\hline 14 & UB2 & 0.942 \\
\hline 15 & UB3 & 0.894 \\
\hline 16 & BI1 & 0.833 \\
\hline 17 & $\mathrm{BI} 2$ & 0.900 \\
\hline 18 & BI3 & 0.855 \\
\hline
\end{tabular}

Dari nilai korelasi tiap variabel yang ada, terlihat bahwa nilai semua korelasi antar variabel yang telah dihasilkan memiliki nilai > 0.7, dan dengan nilai yang dihasilkan tersebut dapat disimpulkan bahwa setiap variabel - variabel pertanyaan yang digunakan dinyatakan Valid. Selain menggunakan hasil laporan dari korelasi, dapat digunakan perhitungan nilai Average Variance Extracted (AVE) untuk dapat mengetahui suatu variabel indicator dinyatakan Valid atau tidak. Dengan nilai dari AVE yang lebih dari 0.5 dapat disimpulkan bahwa konstruksi yang telah dibuat lebih dari setengah variannya sehingga dapat dinyatakan bahwa tingkat validitas dari konstruksi yang diuji dapat dinyatakan Valid. Berikut hasil laporan dari Average Variance Extracted (AVE) pada tiap variabel yang telah diuji

Tabel 2. Hasil perhitungan average variance extracted (AVE)

\begin{tabular}{lll}
\hline $\boldsymbol{N O}$ & $\boldsymbol{V A R I A B \boldsymbol { L }}$ & $\boldsymbol{H A S I L}$ \\
\hline 1 & PE & 0.779 \\
2 & EE & 0.747 \\
3 & SI & 0.699 \\
4 & FC & 0.593 \\
5 & BI & 0.783 \\
6 & UB & 0.745 \\
\hline
\end{tabular}

Dari hasil tabel diatas, dapat dilihat bahwa seluruh nilai AVE dari tiap masing - masing variabel yang telah diuji memiliki nilai diatas 0.5 , sehingga dari hasil yang didapatkan tersebut dapat disimpulkan bahwa variabel yang telah diuji dapat dinyatakan Valid. Guna melihat reabilitas yang digunakan dalam penelitian ini digunakannya metode Cronbach's Alpha dimana suatu variable dapat dinyatakan tingkat reabilitas yang dimilikinya baik jika memiliki nilai Cronbach's Alpha $\geq 0.60$. 
Tabel 3. Hasil uji reabilitas cronbach`s alpha

\begin{tabular}{ccc}
\hline $\boldsymbol{N} \boldsymbol{O}$ & VARIABEL & HASIL \\
\hline 1 & PE & 0.860 \\
2 & EE & 0.836 \\
3 & SI & 0.806 \\
4 & FC & 0.646 \\
5 & BI & 0.859 \\
6 & UB & 0.828 \\
\hline
\end{tabular}

Dan dari hasil yang didapatkan dari tabel diatas dapat disimpulkan bahwa tiap variable yang telah diuji memiliki nilai lebih dari $\geq 0.60$, dengan begitu tiap variable yang telah diuji dapat dinyatakan reliable.

\subsection{Hasil Uji Hipotesis}

Tabel 4. Hasil pengujian hipotesis

\begin{tabular}{|c|c|c|c|}
\hline$N O$ & Variabel & Original Sample & T Statistic $(|O / S T E R R|)$ \\
\hline 1 & $\mathrm{PE} \rightarrow \mathrm{BI}$ & 0.070 & 0.405 \\
\hline 2 & $\mathrm{EE} \rightarrow \mathrm{BI}$ & 0.261 & 1.737 \\
\hline 3 & $\mathrm{SI} \rightarrow \mathrm{BI}$ & 0.470 & 3.694 \\
\hline 4 & $\mathrm{FC} \rightarrow \mathrm{UB}$ & 0.309 & 1.335 \\
\hline 5 & $\mathrm{PE} * \mathrm{AGE} \rightarrow \mathrm{BI}$ & -0.040 & 0.100 \\
\hline 6 & $\mathrm{EE} * \mathrm{AGE} \rightarrow \mathrm{BI}$ & 0.041 & 0.161 \\
\hline 7 & $\mathrm{EE} * \mathrm{EXP} \rightarrow \mathrm{BI}$ & 0.186 & 1.297 \\
\hline 8 & $\mathrm{SI} * \mathrm{AGE} \rightarrow \mathrm{BI}$ & 0.134 & 0.535 \\
\hline 9 & $\mathrm{SI} * \mathrm{EXP} \rightarrow \mathrm{BI}$ & -0.199 & 1.344 \\
\hline 10 & $\mathrm{FC} * \mathrm{AGE} \rightarrow \mathrm{UB}$ & -0.256 & 0.637 \\
\hline 11 & $\mathrm{FC}^{*} \mathrm{EXP} \rightarrow \mathrm{UB}$ & 0.108 & 0.533 \\
\hline 12 & $\mathrm{BI} \rightarrow \mathrm{UB}$ & 0.201 & 1.050 \\
\hline 13 & $\mathrm{BI} * \mathrm{AGE} \rightarrow \mathrm{UB}$ & 0.328 & 0.817 \\
\hline 14 & $\mathrm{BI} * \mathrm{EXP} \rightarrow \mathrm{UB}$ & -0.189 & 1.103 \\
\hline
\end{tabular}

Berikut hasil dari masing - masing pengaruh dari hubungan variabel yang telah diuji:

a) Hipotesis 1 (PE) Performance Expentancy memiliki pengaruh terhadap Behavior Intention (BI) untuk menggunakan sistem Redmine pada grup PRDC ditolak dikarenakan nilai dari variabel $t$-statistic lebih kecil dibandingkan nilai t- tabel $(1,96)$ sehingga Performance Expentancy terhadap Behavior Intention tidak memiliki pengaruh.

b) Hipotesis 2 (EE) Effort Expentancy memiliki pengaruh terhadap Behavior Intention (BI) untuk menggunakan sistem Redmine pada grup PRDC ditolak dikarenakan nilai dari variabel $t$-statistic lebih kecil dibandingkan nilai t-tabel sehingga Effort Expentancy terhadap Behavior Intention tidak memiliki pengaruh.

c) H3 (SI) Social Influence memiliki pengaruh terhadap Behavior Intention (BI) untuk menggunakan sistem Redmine pada grup PRDC diterima dikarenakan variabel $t$-statistic bernilai 3.694 lebih besar dibandingkan nilai t-tabel, dan nilai dari Original Sample sebesar 0.470 sehingga Social Influence memiliki pengaruh positif terhadap Behavior Intention. Untuk variabel control Age (AGE) bernilai positif dan dapat diterima sedangkan Experience (EX) bernilai negatif dan tidak dapat diterima.

d) Hipotesis 4 (FC) Facilitating Condition memiliki pengaruh terhadap Use Behavior (UB) untuk menggunakan sistem Redmine pada grup PRDC ditolak dikarenakan nilai $\mathrm{t}$ - tabel lebih besar dibandingkan dengan nilai $t$ statistic sehingga dapat dikatakan Facilitating Condition tidak memiliki pengaruh terhadap Use Behavior.

e) Hipotesis 5 (BI) Behavioral Intention memiliki pengaruh terhadap Use Behavior (UB) sistem Redmine pada grup PRDC ditolak dikarenakan nilai dari $t$-statistic lebih kecil dibandingkan dengan nilai $\mathrm{t}$ - tabel.

\section{KESIMPULAN}

Berdasarkan analisis yang telah dilakukan, dapat diketahui hal - hal yang mempengaruhi penerapan teknologi informasi pada karyawan grup PRDC (Product Research and Development Center) PT. Anabatic Digital Raya terhadap aplikasi Redmine dengan menggunakan metode UTAUT (Unified Theory of Acceptance and Use of Technology). Penerimanaan dan penggunaan sistem Redmine pada karyawan grup PRDC didasari dengan Social Influence, dengan pengaruh dari sekitar baik dari senior/atasan maupun sesama karyawan yang membuat sehingga menggunakan sistem aplikasi Redmine guna menunjang kinerja dari karyawan grup PRDC. 


\section{DAFTAR PUSTAKA}

[1] V. Venkatesh, J. Y. Thong and X. Xu, "Consumer Acceptance and Use of Information Technology : Extending the Unified Theory of Acceptance and Use of Technology," MIS Quarterly, vol. 2012, p. 1, 2012.

[2] F. Davis, "Perceives Usefulness, Percieves Ease of Use, and User Acceptance of Information Technology," MIS Quartely, vol. 13, pp. 319 - 339, 1989.

[3] J. Hartono, Sistem Informasi Keperilakuan, Yogyakarta: Penerbit Andi, 2007.

[4] M. Nasir, "Evaluasi Penerimaan Teknologi Informasi Mahasiswa di Palembang Menggunakan Model UTAUT," Palembang : Fakultas Ilmu Komputer : Universitas Bina Darma, 2013.

[5] V. Venkatesh, M. M.G, D. G.B and D. F.D, "User acceptance of - information technology: toward a unified view," MIS Quarterly, vol. 27, pp. 425 - 478, 2003.

[6] V. Venkatesh and F. Davis, "A Theoritical Extension of the Technology Acceptance Model: Four Longitudinal Field Studies," Management Science, Vols. 46, No.2, pp. 186-204, 2000.

[7] B. Bungin, Metodologi Penelitian Kuantitatif, Jakarta: Kencana, 2005. 